\title{
Salt-Inducible Kinase 1 (SIK1) is Induced by Alcohol and Suppresses Microglia Inflammation via NF-KB Signaling
}

\author{
Yu Zhang ${ }^{a}$ Weida Gao ${ }^{b}$ Kongbin Yang ${ }^{c}$ Haiquan Tao ${ }^{b}$ Haicheng Yang ${ }^{b}$ \\ aDepartment of Neurology, The Fourth Affiliated Hospital of Harbin Medical University, Harbin, \\ bDepartment of Neurosurgery, The Second Affiliated Hospital of Harbin Medical University, Harbin, \\ 'Department of Neurosurgery, The First Affiliated Hospital of Harbin Medical University, Harbin, China
}

\section{Key Words}

Salt-Inducible Kinase $1 \cdot$ Alcohol • Brain Inflammation • NF-kB Signaling

\begin{abstract}
Background/Aims: Alcohol consumption has been shown to cause neuroinflammation and increase a variety of immune-related signaling processes. Microglia are a crucial part of alcohol-induced neuroinflammation and undergo apoptosis. Even though the importance of these inflammatory processes in the effects of alcohol-related neurodegeneration have been established, the mechanism of alcohol-induced microglia apoptosis is unknown. In prior research, we discovered that alcohol increases expression of salt-inducible kinase 1 (SIK1) in rodent brain tissue. In this study, we sought to determine what role SIKI expression plays in alcohol-induced neuroinflammation as well as whether and by what mechanism it regulates microglia apoptosis. Methods: Adult C57BL/6 mice were divided into four groups and for 3 weeks treated with either $0 \%, 5 \%, 10 \%$, or $15 \%$ alcohol during 3 hour periods. The mice were sacrificed and their brains excised for analysis. Additionally, primary microglia were isolated from neonatal mice. SIK1 expression in alcohol-treated brain tissue and microglia was analyzed via RT-PCR and western blotting. TUNEL staining, caspase-3, and caspase-9 activity assays were performed to evaluate microglial apoptosis. Cell fluorescence staining and NF-KB luciferase activity assays were used to evaluate the effects of SIK1 expression on the NF-KB signaling pathway. Results: SIK1 expression was increased in the brains of mice that consumed alcohol, and this effect was seen in mouse primary microglia. SIK1 knockdown in microglia increased alcohol-induced apoptosis in these cells. Furthermore, SIK1 reduced NFKB signaling pathway factors, and SIK1 knockdown in microglia promoted alcohol-induced NF- $K B$ activity. TUNEL staining, caspase- 3 , and caspase- 9 activity assays consistently revealed that alcohol-induced microglial apoptosis was inhibited by depletion of p65. Finally, we determined that NF-KB signaling is required for alcohol-induced, SIK1-mediated apoptosis in microglia. Conclusion: This study establishes for the first time not only that SIKI is crucial to
\end{abstract}

Yu Zhang, Weida Gao and Kongbin Yang contributed equally to this work.

Haiquan Tao and

Haicheng Yang
Department of Neurosurgery, The Second Affiliated Hospital of Harbin Medical

University ,148 Baojian Road, 150081 Harbin, (China)

Tel.86-0451-86605222, E-Mail taohaiquan7824@163.com/yanghaicheng999@sina.com 


\section{Cellular Physiology Cell Physiol Biochem 2018;47:1411-1421 \\ \begin{tabular}{c|c} 
DOI: 10.1159/000490831 & $\begin{array}{l}\text { O } 2018 \text { The Author(s). Published by S. Karger AG, Basel } \\
\text { www.karger.com/cpb }\end{array}$
\end{tabular} \\ Zhang et al.: SIK1 is Induced by Alcohol and Suppresses Inflammation}

regulating alcohol-induced microglial apoptosis, but also that the NF-KB signaling pathway is required for its activity. Overall, our results help elucidate mechanisms of alcohol-induced neuroinflammation.

\section{Introduction}

Microglial activation is a hallmark of many neurodegenerative processes, including those induced by acute alcohol use [1,2]. Changes in microglia activity and increases in pro-inflammatory cytokines are thought to both result from and contribute to alcohol pathologies $[3,4]$. The effects of alcohol exposure on the immune system are complex, and adding to this complexity is the fact that microglia can function in different contexts as either neuroprotective or cytotoxic agents [5]. On the one hand, microglia exacerbate alcoholinduced neuroinflammation and oxidative stress; on the other, they help establish cell homeostasis following alcohol exposure [5-7]. Much research has focused on the impacts of alcohol exposure on neuronal cytotoxicity, but far fewer studies have explored the effects of alcohol on microglial integrity $[8,9]$. Through the experiments performed here, we sought to investigate the impact of alcohol use on neuroinflammation and microglial toxicity.

Microglia are the brain's resident macrophage [10]. They are highly active in both the healthy and pathological central nervous system (CNS), responding to disturbances in neurons, the blood brain barrier (BBB), and blood vessels, among other constituents, to maintain CNS homeostasis [11]. It had long been assumed that microglial activation was a singular state, but more recent work has established that microglia adopt a number of phenotypes, depending on the character of the CNS challenge [1,12]. Crucially, microglia can express both pro- and anti-inflammatory mediators in response to immune insults [13, 14]. While it is clear that acute and chronic alcohol exposure induce microglial activation, it is unknown to what degree the microglial phenotype is a cause or consequence of alcoholinduced neuroinflammation or subsequent neurodegeneration.

Alcohol induces a number of changes in the immune system, generally resulting in a proinflammatory state in the CNS [4, 15-18]. For example, alcohol has been shown to stimulate toll-like receptor 4 (TLR4) and toll-like receptor 2 (TLR2) expression in microglia, thereby increasing pro-inflammatory mediators, reactive oxygen species, and neuronal apoptosis $[8,9,19]$. Additionally, in a rat model of binge drinking, hippocampal microglia underwent increased activation in response to alcohol exposure [20]. However, neurotrophic microglia have also been implicated in recovery from alcohol exposure, suggesting that partial microglial activation in response to the cytotoxicity and inflammation induced by alcohol can actually remediate the negative effects of the exposure [21]. The complexity of microglial responses to alcohol necessitates further study of microglia integrity in an alcoholic brain milieu.

In 2014, our group examined the CNS gene expression profiles of rats experiencing acute alcohol exposure [22]. We identified a number of upregulated genes and transcription factors, in addition to 20 highly connected hub genes that may be involved in the immune response to acute alcohol exposure. Among these was salt-inducible kinase 1 (SIK1), a serine/threonine protein kinase that was originally identified in the adrenal glands of rats fed high salt diets [23]. Even though SIK1 has largely been investigated in the extracranial context of adrenal physiology and pathology [24-26], Feldman et al. demonstrated that SIK mRNA is significantly increased in the rat hippocampus and cortex following kainic acid-induced seizures [27]. Since then, a number of studies have implicated SIK1 in brain pathology [28-30], including one that identifies de novo SIK1 mutations as the cause of certain developmental epilepsies [31]. In the present study, we have established that SIK1 activity is crucial for regulating alcohol-induced microglial apoptosis through its effects on the NF- $\kappa B$ signaling pathway.

\section{KARGER}




\section{Cellular Physiology Cell Physiol Biochem 2018;47:1411-1421 \begin{tabular}{l|l} 
and Biochemistry Published online: June 22, 2018 & $\begin{array}{l}\text { D } 2018 \text { The Author(s). Published by S. Karger AG, Basel } \\
\text { www.karger.com/cpb }\end{array}$
\end{tabular} Zhang et al.: SIK1 is Induced by Alcohol and Suppresses Inflammation}

\section{Materials and Methods}

\section{Animals}

Animal studies were approved by the Institutional Animal Care and Use Committee (IACUC) of Harbin Medical University. We feed the mice as our previous work described [32]. 36 C57BL/6 mice (5 to 6 weeks old) were randomly divided into four groups. Alcohol consumption followed a two-bottle choice-drinking in the dark paradigm [33]. For 3 weeks, the animals received $0 \%, 5 \%, 10 \%$, or $15 \%$ alcohol from separate bottles during a $3 \mathrm{~h}$ period starting three hours into the dark cycle to avoid side preference and were pairfed diets with equal amounts of water. Study mice were sacrificed under anesthesia and the brain tissues were excised for analysis.

\section{Culture of primary microglial cells}

Mouse primary microglial cell cultures were prepared as previously described [22, 34]. In brief, cerebral cortices from 1-day-old neonatal mice were dissected, stripped of their meninges and vessels after washing in ice-cold PBS, and digested with $0.25 \%$ trypsin for $30 \mathrm{~min}$ at $37^{\circ} \mathrm{C}$. Trypsin activity was stopped with an equal volume of RPMI medium (Invitrogen, Carlsbad, CA) containing 10\% fetal bovine serum (FBS) (Invitrogen), $100 \mathrm{U} / \mathrm{mL}$ penicillin, and $100 \mathrm{lg} / \mathrm{mL}$ streptomycin (Invitrogen). The tissue suspension was centrifuged, supernatant removed, and the pelleted cells made into a single cell suspension in culture medium by repeated pipetting followed by passage through a $40 \mathrm{~mL}$ cell strainer and then centrifuged at $1250 \times \mathrm{g}$ for $5 \mathrm{~min}$ at room temperature. Supernatant was discarded and the pellet was resuspended in $3 \mathrm{~mL}$ of $70 \%$ Percoll and transferred to a $15 \mathrm{~mL}$ conical tube. $6 \mathrm{~mL}$ of $50 \%$ Percoll followed by $2 \mathrm{~mL}$ of $2 \%$ FBS and $0.2 \%$ glucose in PBS were layered on top of the $70 \%$ Percoll cell suspension and centrifuged at $2400 \times \mathrm{g}$ for $30 \mathrm{~min}$ at room temperature. The layer containing enriched microglia was collected from the interface between the $70 \%$ and $50 \%$ Percoll phases and washed twice with $1 \mathrm{~mL}$ of PBS containing $2 \%$ FBS and $0.2 \%$ glucose and centrifuged at $1250 \times \mathrm{g}$ for $5 \mathrm{~min}$ at room temperature. Isolated brain microglia were seeded in growing medium (250, 000 cells/mL) and non-adherent cells were removed by washing cells with PBS 1 $\mathrm{h}$ after plating. Medium was replaced every 3-4 days, and cultures were used for between 12 and 20 days. For alcohol stimulation, cells were incubated with medium containing $50 \mathrm{mM}$ alcohol at $37{ }^{\circ} \mathrm{C}, 5 \% \mathrm{CO}_{2}$ and harvested $12 \mathrm{~h}$ post-treatment.

\section{RT-PCR}

RNA was extracted using TRIzol (Invitrogen) according to the manufacturer's instructions. cDNA was transcribed from $1 \mathrm{mg}$ of total RNA using Reverse Transcription System (Promega, Madison, WI). SYBR-Green-based real time quantitative PCR was performed using the iCycler (Bio-Rad Laboratories Inc, Hercules, CA). Comparative threshold cycle (Ct) method was used to calculate expression relative to control groups. The final results were expressed as fold changes between the sample and the controls corrected with internal control. Sense and antisense primer sequences were: SIK1 sense 5'- TGGACGTCTGGAGCCTCGGT-3'; SIK1 antisense 5'- AGAGTGGGGTCGGCCTGCAT-3'; $I L$-1 $\beta$ sense 5'-AATCTCACAGCAGCACATCAA-3'; $I L-1 \beta$ antisense 5'-AGCCCATACTTTAGGAAGACA-3'; IL-6 sense 5'-TGGAGTCACAGAAGGAGTGGCTAAG-3'; IL-6 antisense 5'-TCTGACCACAGTGAGGAATGTCCAC-3'. TNF- $\alpha$ sense 5'-CCCCTCAGCAAACCACCAAGT-3'; TNF- $\alpha$ antisense 5'-CTTGGGCAGATTGACCTCAGC-3'; $\beta$-actin sense 5'-CCACACCCGCCACCAGTTCG-3'; $\beta$-actin antisense 5'-CCCATTCCCACCATCACACC-3'.

\section{Western blot}

Cells or tissues were harvested and lysed with ice-cold lysis buffer (50 mM Tris-HCl, pH 6.8, $32 \mathrm{mM}$ 2 -ME, $2 \%$ SDS, $10 \%$ glycerol). After centrifugation $\left(20,000 \times\right.$ g, $\left.10 \mathrm{~min}, 4^{\circ} \mathrm{C}\right)$, proteins were separated by $10 \%$ SDS PAGE and transferred to polyvinylidene difluoride membranes (Bio-rad). After blocking with 5\% BSA in TBST, membranes were incubated with primary antibodies, followed by HRP-linked secondary antibodies (Santa Cruz, CA). Bound antibodies were detected by SuperSignal West Pico Chemiluminescent Substrate kit (Pierce, Rockford, IL) according to the manufacturer's instructions. Antibodies against p65, Histone H1, and $\beta$-actin were purchased from Santa Cruz Biotechnologies (Santa Cruz). Anti-SIK1, anti-IKK $\alpha / \beta$, and anti$\mathrm{p}$-IKK $\alpha / \beta$ antibodies were obtained from Abcam (Cambridge, MA) Protein levels of Histone H1 and $\beta$-actin were used as loading controls.

\section{KARGER}




\section{Cellular Physiology Cell Physiol Biochem 2018;47:1411-1421 \begin{tabular}{l|l} 
DOI: 10.1159/000490831 & and Biochemistry \\
Published online: June 22, 2018 & $\begin{array}{l}\text { 2018 The Author(s). Published by S. Karger AG, Basel } \\
\text { www.karger.com/cpb }\end{array}$
\end{tabular} \\ Zhang et al.: SIK1 is Induced by Alcohol and Suppresses Inflammation}

\section{TUNEL Staining}

TUNEL staining was performed using the DeadEnd Fluorometric TUNEL System (Promega,Madison, WI) according to the manufacturer's protocol. Briefly, cells were grown on chambered culture slides, fixed with 4\% PFA for $2 \mathrm{~h}$ at room temperature, and permeabilized with $0.2 \%$ Triton X-100 in PBS for 5 min. Cells were washed again with PBS and equilibrated with $100 \mu \mathrm{L}$ of equilibration buffer at room temperature for $10 \mathrm{~min}$. Slides were covered with $50 \mu \mathrm{L}$ of terminal deoxynucleotidyl transferase reactionmixture for 60 min in a humidified chamber. The reaction was stopped with 2x SSC for $15 \mathrm{~min}$. Nuclei were visualized by DAPI staining.

\section{Caspase Activity Assays}

Microglial cells $\left(1 \times 10^{4}\right)$ were incubated in 96-well plates for $24 \mathrm{~h}$, and caspase- 3 activity was measured using the caspase- 3 and caspase- 9 assay kits (Ambion,Austin, TX) according to the manufacturer's protocol. Briefly, the cells were incubated with lysis buffer on ice for $10 \mathrm{~min}$ and collected via 10, 000 xg centrifugation for $10 \mathrm{~min}$. Protein $(100 \mu \mathrm{g})$ from each sample was incubated with specific colorimetric tetrapeptides Asp-Glu-Val-Asp-p-nitroaniline (pNA; specific substrate of caspase-3) or Leu-Glu-His-Asp-pNA (specific substrate of caspase-9) at $37^{\circ} \mathrm{C}$ for $60 \mathrm{~min}$. The activity levels of caspase- 3 and caspase- 9 were quantified using a spectrophotometer at $405 \mathrm{~nm}$, and the data were normalized to the control group.

\section{Immunofluorescent staining}

Microglial cells were seeded in 4-well chamber slides in triplicate. Cells were then fixed with freshly prepared 4\% PFA for 15 min and permeabilized with 0.5\% Triton X-100 for $15 \mathrm{~min}$. After $1 \mathrm{~h}$ incubation with $10 \%$ normal goat serum, cells were incubated with rabbit anti-p65 (1:100, Santa Cruz). After washing with PBS, a FITC-conjugated goat anti-rabbit secondary antibody (1:1000, Invitrogen) was used to probe the primary antibody for $1 \mathrm{~h}$. Thereafter, the cells were mounted with DAPI containing mount media and scanned under an Olympus fluorescence microscope. Cells probed with only a secondary antibody were used as negative controls.

\section{Statistical analysis}

Data were expressed as mean \pm SD from at least three separate experiments. Differences between groups were analyzed using oneway ANOVA. $p<0.05$ was considered statistically significant.

\section{Results}

SIK1 is increased in alcohol-treated microglial cells and brain tissues

From our previous microarray data, we found that SIK1 is induced by alcohol in rodent brain tissue [22]. To investigate whether SIK1 plays a role in alcohol-induced rodent brain apoptosis and inflammation, we performed RT-PCR to

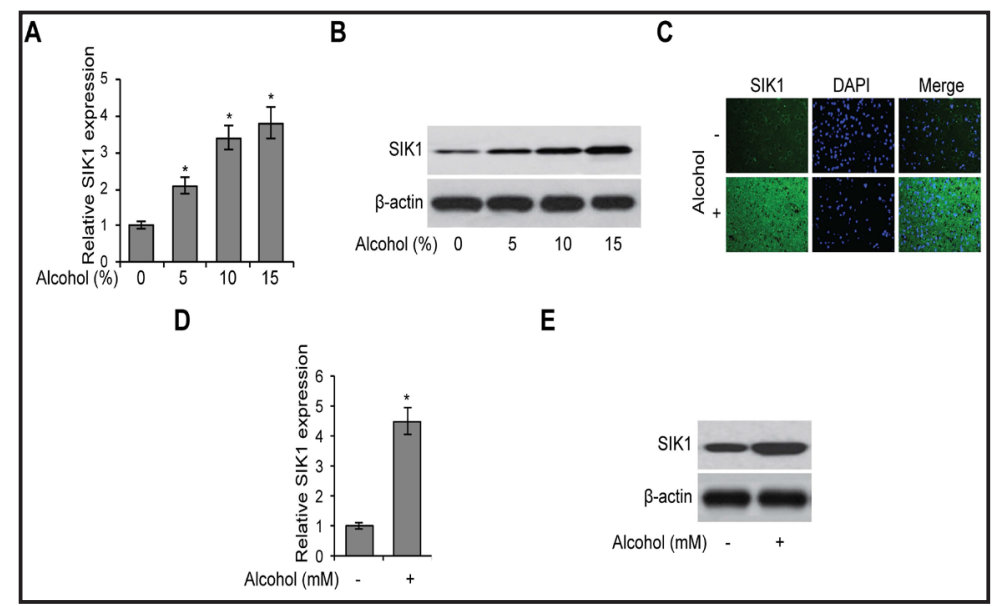

Fig. 1. SIK1 is increased in alcohol-treated microglial cells and brain tissues. (A) RT-PCR analysis of SIK1 mRNA expression in the brain of mice fed with alcohol $(0 \%, 5 \%, 10 \%$ or $15 \%)$ for 3 weeks. (B) Western blot analysis of SIK1 protein expression in the brain of mice fed with alcohol $(0 \%, 5 \%, 10 \%$ or $15 \%)$ for 3 weeks. (C) Tissue fluorescence staining of SIK1 in the brains of mice fed with $0 \%$ alcohol (-) or $15 \%$ alcohol (+) for 3 weeks. (D) RT-PCR analysis of SIK1 mRNA expression in mouse microglial cells treated with alcohol (100 mM). (E) Western blot analysis of SIK1 protein expression in mouse microglial cells treated with alcohol (100 $\mathrm{mM}$ ). ${ }^{*} \mathrm{p}<0.01$ compared with the control group. 
analyze SIK1 mRNA and protein expression in the brain of mice fed with different concentrations of alcohol. We found that SIK1 is increased in mouse brains after alcohol consumption (Figs. 1A and 1B). Brain tissue fluorescence staining of SIK1 was then performed in mice fed with or without alcohol (15\%). SIK1 staining in the alcohol group was stronger than in the control group in both microglial cells and neurons (Fig. 1C). We focused on microglial cells mediated brain inflammation. We isolated mouse primary microglial cells from newborn mice

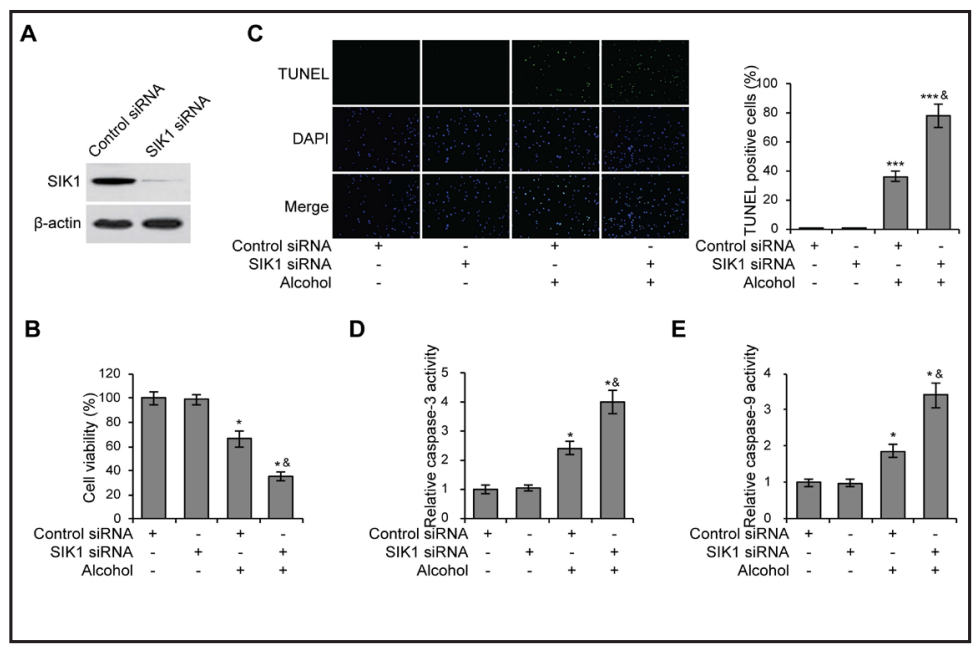

Fig. 2. Knockdown of SIK1 increased alcohol-induced apoptosis in microglia. (A) SIK1 expression measured by western blotting after SIK1 siRNA transfection. (B to E) Cell viability assay (B), TUNEL staining (C), caspase-3 (D), and caspase-9 (E) activity assays in SIK1-knockdown microglia treated or not treated with alcohol $(100 \mathrm{mM}) .{ }^{*} \mathrm{p}<0.01$ compared with the control group not treated with alcohol; ${ }^{*} \mathrm{p}<0.01$ compared with the control group treated with alcohol. and treated the cells with $100 \mathrm{mM}$ alcohol. We then performed RT-PCR and western blots to analyze SIK1 expression $12 \mathrm{~h}$ post-treatment. We found that expression of SIK1 was significantly higher after alcohol treatment compared with control (Fig. 1D and 1E). Together, these results indicate that alcohol-treated microglia have increased expression levels of SIK1.

\section{Knockdown of SIK1 increases alcohol-induced apoptosis in microglial cells}

To explore the role of SIK1 in alcohol-induced microglial cell apoptosis, we first transfected mouse microglial cells with control or SIK1 siRNA for $24 \mathrm{~h}$ and exposed the cells to alcohol $(100 \mathrm{mM})$. Knockdown efficiency was confirmed by western blotting (Fig. 2A). As expected, cell viability decreased by $30 \%$ in the alcohol-treated as compared untreated cells. However, the viability of SIK1-knockdown cells decreased by almost $50 \%$ with alcohol treatment (Fig. 2B). TUNEL staining, caspase- 3 and caspase- 9 activity assays and consistently showed that alcohol-induced cell apoptosis was promoted by depletion of SIK1 (Fig. 2C to 2E). Overall, these results suggest that SIK1 is protective against alcohol-induced apoptosis in microglia.

\section{SIK1 regulates $N F-\kappa B$ signaling activity}

To investigate whether SIK1 regulates alcohol-induced rodent brain inflammation, RTPCR analysis was used to evaluate expression of inflammatory factors in SIK1 knockdown microglial cells. $I L-1 \beta, I L-6$, and TNF- $\alpha$ expression was stimulated by alcohol and further promoted by SIK1 knockdown (Figs. 3A to 3C). Pearson correlation analysis showed a negative correlation between SIK1 and inflammatory factors $(I L-1 \beta, I L-6, T N F-\alpha)$ in the brain from nine mice fed with alcohol (Figs. 3D to 3F). To study whether NF- $\kappa$ B signaling is related to SIK1-mediated inflammation induced by alcohol, we treated mouse microglial cells with alcohol after SIK1 knockdown and extracted nuclear proteins for p65 expression. Alcohol promoted p65 nuclear translocation, which was enhanced by SIK1 knockdown (Fig. 4A). Cell fluorescence staining and NF- $\kappa B$ luciferase activity assays confirmed that knockdown of SIK1 in microglial cells further promoted NF- $\kappa$ B activity induced by alcohol (Figs. 4B and 4C). Mechanistically, knockdown of SIK1 elevated phosphorylated IKK $\alpha / \beta$ and subsequently stimulated NF- $\kappa B$ signaling activity (Fig. 4D). 


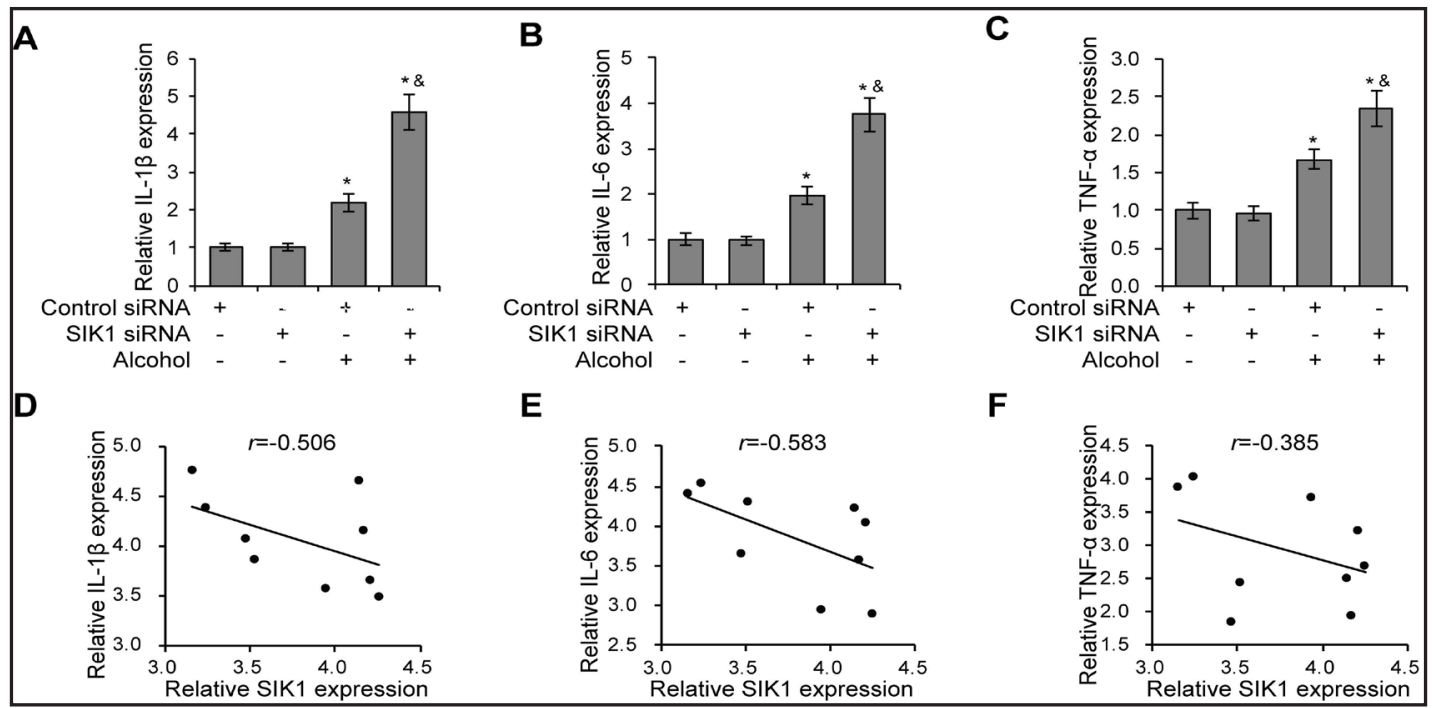

Fig. 3. There is a negative correlation between SIK1 expression and pro-inflammatory cytokines in alcoholinduced microglia and brain tissues. (A to C) RT-PCR analysis of IL-1 $\beta$ (A), IL-6 (B), and TNF- $\alpha$ (C) mRNA expression in mouse microglia treated or not treated with alcohol $(100 \mathrm{mM})$ after SIK1 siRNA transfection. (D to F) Pearson correlation analysis between IL-1 $\beta$ and SIK1 (D), IL-6 and SIK1 (E), and TNF- $\alpha$ and SIK1 (F). ${ }^{*} \mathrm{p}<0.01$ compared with the control group not treated with alcohol; ${ }^{\mathrm{p}} \mathrm{p}<0.01$ compared with the control group treated with alcohol.

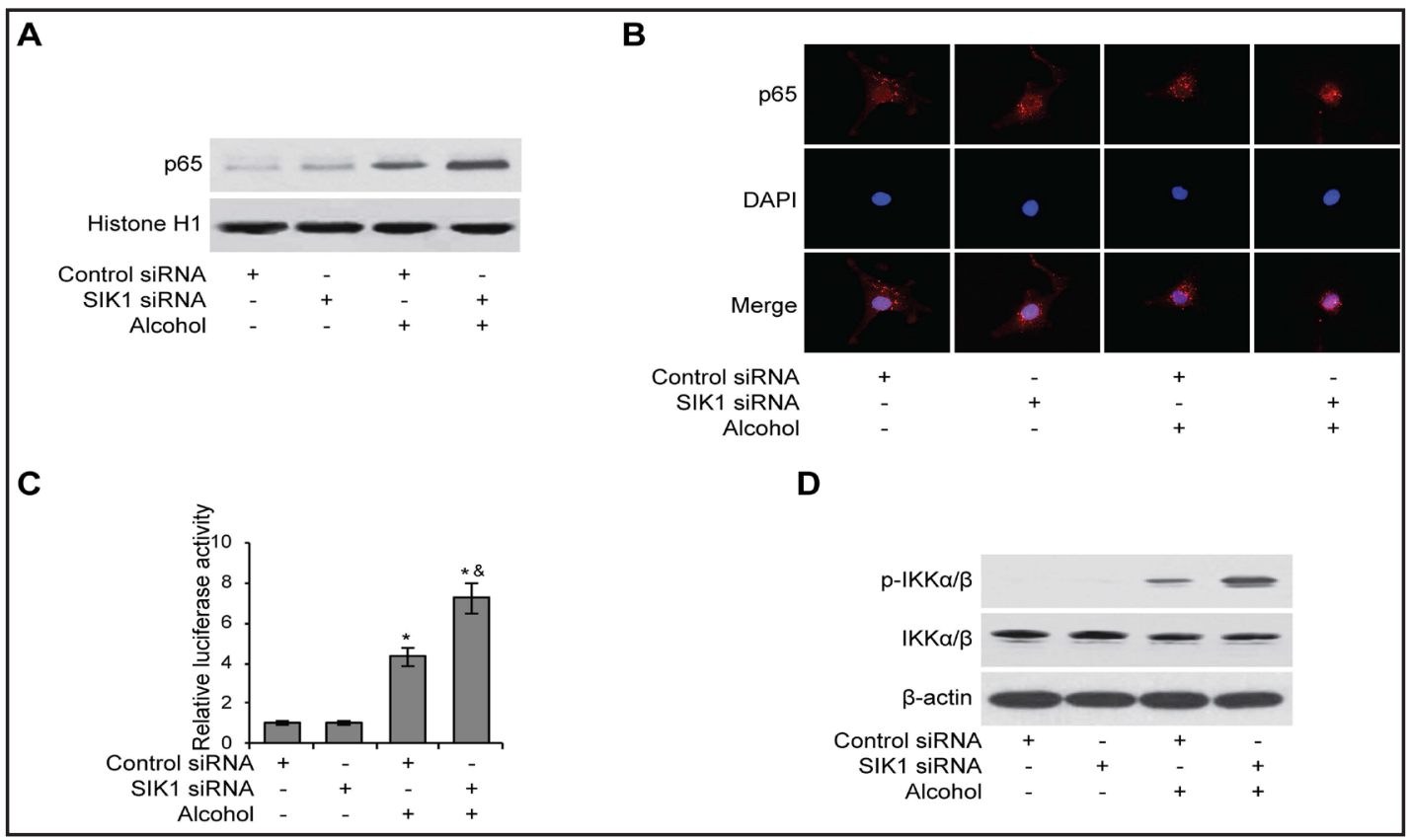

Fig. 4. Knockdown of SIK1 promotes NF- $\kappa B$ signaling activity. (A to D) Western blot analysis of nuclear p65 protein levels (A), Cell fluorescence staining of p65 (B), Relative NF- $\kappa B$ luciferase activity (C), Western blot analysis of IKK $\alpha / \beta$ and $\mathrm{p}-\mathrm{IKK} \alpha / \beta$ in mouse microglia treated or not treated with alcohol (50mM) after SIK1 siRNA transfection (D). ${ }^{*} \mathrm{p}<0.01$ compared with the control group not treated with alcohol; ${ }^{\&} \mathrm{p}<0.01$ compared with the control group treated with alcohol.

\section{$N F-\kappa B$ signaling plays a role in alcohol-induced apoptosis of microglial cells}

In order to detect the role of p65 in alcohol-induced microglial cell apoptosis, we first transfected mouse microglial cells with control or p65 siRNA for $24 \mathrm{~h}$ and exposed the cells 
to alcohol $(100 \mathrm{mM})$. Knockdown efficiency was confirmed by western blotting (Fig. 5A). We performed cell viability assays and found that cell viability decreased by $40 \%$ in the alcohol-treated as compared to cells in the control group. However, the viability of p65-knockdown cells decreased by only $20 \%$ with alcohol treatment (Fig. 5B). TUNEL staining, caspase-3, and caspase-9 activity assays consistently revealed that alcohol-induced cell apoptosis was inhibited by depletion of p65 (Figs. 5C to 5E). Together, these findings indicate that NF- $\mathrm{KB}$ signaling promotes alcohol-induced microglial apoptosis.

$N F-\kappa B$ signaling is required for SIK1mediated apoptosis induced by alcohol in microglial cells

We next investigated whether SIK1 regulates alcohol-induced inflammation through the NF- $\mathrm{KB}$ signaling pathway. SIK1 was further decreased in p65 knockdown microglial cells. These cells were subjected to cell viability, TUNEL staining, caspase-3 and caspase-9 activity assays (Figs. 6A to 6D). As compared to p65 knockdown cells, further downregulation of SIK1 did not affect microglial cell apoptosis. These results strongly suggest that NF-KB signaling is required for SIK1-mediated apoptosis induced by alcohol.

\section{Discussion}

Despite being present in almost all societies throughout history, alcohol consumption continues to contribute significantly to the global burden of disease [35]. Acute alcohol

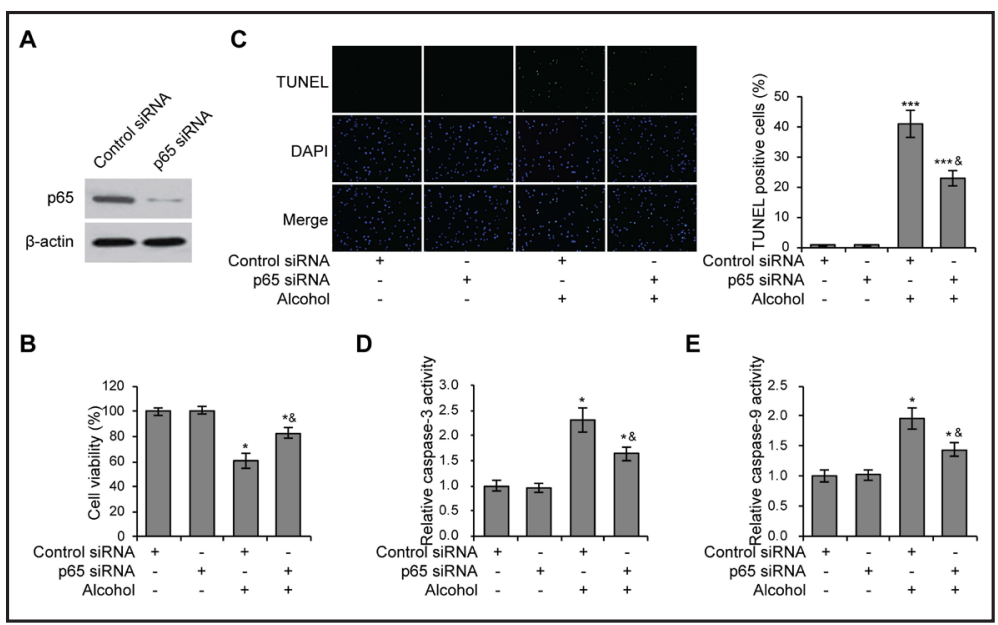

Fig. 5. NF- $\mathrm{BB}$ signaling plays a role in alcohol-induced apoptosis of microglia. (A) p65 expression measured by western blotting after p65 siRNA transfection. (B to E) Cell viability assay (B), TUNEL staining (C), caspase-3 (D), and caspase-9 (E) activity assays in p65-knockdown microglia treated or not treated with alcohol $(100 \mathrm{mM}) .{ }^{*} \mathrm{p}<0.01$ compared with the control group not treated with alcohol; ${ }^{\circledR} \mathrm{p}<0.01$ compared with the control group treated with alcohol.

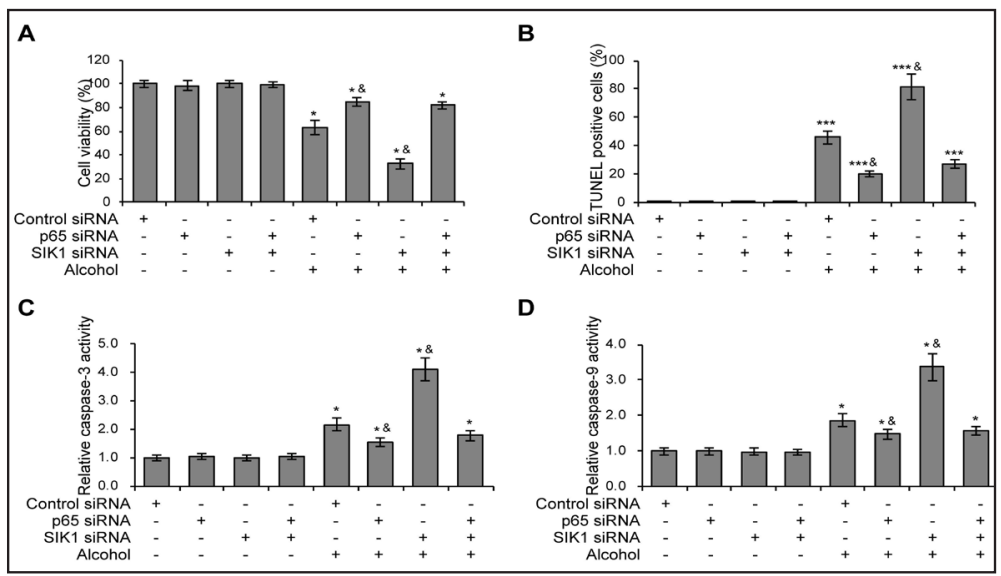

Fig. 6. NF- $\kappa \mathrm{B}$ signaling is required for SIK1-mediated apoptosis induced by alcohol in microglia. (A to D) Cell viability assay (A), TUNEL staining (B), caspase-3 (C), and caspase-9 (D) activity assays in p65-, SIK1-, or both p65- and SIK1- knockdown microglia treated or not treated with alcohol $(100 \mathrm{mM}) .{ }^{*} \mathrm{p}<0.01$ compared with the control group not treated with alcohol; ${ }^{\text {p }}<0.01$ compared with the control group treated with alcohol. 


\section{Cellular Physiology Cell Physiol Biochem 2018;47:1411-1421 \\ \begin{tabular}{l|l} 
and Biochemistry Published online: June 22, 2018 & $\begin{array}{l}\text { (c) } 2018 \text { The Author(s). Published by S. Karger AG, Basel } \\
\text { www.karger.com/cpb }\end{array}$
\end{tabular}}

Zhang et al.: SIK1 is Induced by Alcohol and Suppresses Inflammation

intoxication is a risk factor for myriad clinical conditions, including brain damage, white matter atrophy, and eventual neurodegeneration [36,37]. One consequence of alcohol consumption that likely contributes to its adverse effects is alcohol-induced neuroinflammation. Alcohol generates a pro-inflammatory environment both extracranially and intracranially, where there is a relatively long-lasting increase in pro-inflammatory cytokines (TNF $\alpha$, IL-1 $\beta$, and MCP-1) [38, 39]. The brains of human alcoholics were shown to have increases in both MCP-1 and microglial activation, along with increased microglial expression of Iba-1 and/or GluT ${ }_{5}$ [17]. Yet, apart from their potential role in alcohol-induced cytotoxicity and neuroinflammation, microglia also likely help restore cell homeostasis following alcohol exposure [1,13]. In this study, we have provided insight into how the gene SIK1 regulates the NF- $\mathrm{KB}$ signaling pathway, ultimately to reduce alcohol-induced microglial apoptosis.

While there is much research into alcohol-induced neuronal toxicity, relatively little is known about the effects of alcohol consumption on microglial integrity [40]. Microglia are highly responsive to neurodegenerative insults and adopt a number of phenotypes, depending on the type of CNS challenge [41]. In an inflammatory state, such as that generated by alcohol consumption, microglia contribute to the production of reactive oxygen species, which have neurotoxic effects, including to oligodendrocytes, whose loss contributes to certain neurodegenerative diseases $[2,41]$. Microglia, as the primary immune effectors of the CNS, function similarly to macrophages in that they are antigen presenting cells (APCs) and travel to the site of tissue damage to secrete cytokines and other pro-inflammatory factors $[42,43]$. However, microglia also have a strong neuroprotective effect, which can heighten in a neurotoxic milieu [44]. For example, microglia have been shown to effectively scavenge oxygen-derived free radicals during excitotoxin-induced neurodegeneration [45]. Researchers have also demonstrated not only that microglia contribute to maintaining neural homeostasis, but also that they promote beneficial circuit-level alterations such as synaptic plasticity through brain-derived neurotrophic factor (BDNF) signaling [46]. Microglia similarly increase trophin-mediated healing responses following spinal cord injury [47]. That we found a significant increase in alcohol-induced microglial apoptosis in our rodent model of acute alcohol use suggests the short- and long-term neurotoxic effects of alcohol use may be due in part to reductions in the reparative activity of microglia. Interestingly, alcohol could reduced Inflammatory Response in Human Lung Epithelial Cells [48].

We began exploring the cause of alcohol-induced microglial apoptosis by examining the expression levels of SIK1, which we had previously shown to be upregulated in the brains of rats experiencing acute alcohol exposure [22]. Indeed, in the present study we found that expression of SIK1 was significantly higher after alcohol treatment compared with control. Using TUNEL staining, caspase-3, and caspase-9 activity assays, we then demonstrated that SIK1 depletion promoted alcohol-induced microglial apoptosis-suggesting that SIK1 exerts a protective effect on microglia in the context of acute alcohol consumption. We then found that expression of inflammatory mediators $I L-1 \beta, I L-6$, and TNF- $\alpha$ was stimulated by alcohol and further promoted by SIK1 knockdown. Furthermore, cell fluorescence staining and NF$\kappa \mathrm{B}$ luciferase activity assays indicated that SIK1 knockdown in microglia promoted alcoholinduced NF- $\kappa B$ activity. Ultimately, we established through the use of p65 knockdown cells that NF- $\kappa \mathrm{B}$ activity is in fact necessary for SIK1-mediated, alcohol-induced microglial apoptosis. SIK1 has been reported to interacts with TGF- $\beta$-activated kinase 1-binding protein 2 (TAB2) and interrupt the complex of TAB2-TNF receptor-associated factor 6 (TRAF6). Thereby inhibits TLR4-mediated NF- $\kappa B$ signaling [49]. Microglia are the primary source of the pro-inflammatory cytokine and contributed to neuroinflammation $[50,51]$. Though we found expression of Sik1 in both microglia and neuron, we focused on microglia-mediated neuroinflammation in this study. The role of Sik1 in neuronal development needs further investigation.

The NF- $\mathrm{B}$ signaling pathway contributes to alcohol-induced neuroinflammation [52]. In fact, the anti-inflammatory xanthohumol (XN) has been shown to inhibit microglial inflammatory responses, in part through reducing NF- $\kappa B$ signaling activation [53]. While it is clear that the NF- $\kappa \mathrm{B}$ signaling pathway is implicated in both alcohol-induced 


\section{Cellular Physiology Cell Physiol Biochem 2018;47:1411-1421 \begin{tabular}{l|l} 
and Biochemistry Published 10.1159/000490831 2018 & $\begin{array}{l}\text { (c) 2018 The Author(s). Published by S. Karger AG, Basel } \\
\text { www.karger.com/cpb }\end{array}$ \\
\hline
\end{tabular} \\ Zhang et al.: SIK1 is Induced by Alcohol and Suppresses Inflammation}

neuroinflammation and microglial activation, it is less known whether its activity is destructive or restorative. In the present study, we have shed some light on this question by establishing that NF- $\mathrm{KB}$ signaling is necessary for SIK1-mediated, alcohol induced microglial apoptosis-a response that likely impedes the neurotrophic functions of microglia following alcohol exposure. However, longer term studies are needed to determine to what degree alcohol-induced microglial apoptosis contributes to the exacerbation or prevention of alcohol use-related neurodegeneration.

\section{Acknowledgements}

This work was supported by Heilongjiang Province post-doctoral funding (LBH-Z16); Grant of Heilongjiang Province Health Department (2010068); Doctor grant of The Second Affiliated Hospital of Harbin Medical University (BS2013-17).

\section{Disclosure Statement}

No conflict of interests exists.

\section{References}

1 Marshall SA, McClain JA, Kelso ML, Hopkins DM, Pauly JR, Nixon K: Microglial activation is not equivalent to neuroinflammation in alcohol-induced neurodegeneration: The importance of microglia phenotype. Neurobiol Dis 2013;54:239-251.

-2 Lull ME, Block ML: Microglial activation and chronic neurodegeneration. Neurotherapeutics 2010;7:354365.

-3 Crews FT, Bechara R, Brown LA, Guidot DM, Mandrekar P, Oak S, Qin L, Szabo G, Wheeler M, Zou J: Cytokines and alcohol; in Alcohol Clin Exp Res. England, 2006, vol. 30, p.^pp. 720-730.

-4 Topper LA, Baculis BC, Valenzuela CF: Exposure of neonatal rats to alcohol has differential effects on neuroinflammation and neuronal survival in the cerebellum and hippocampus. J Neuroinflammation 2015;12:160.

5 Ahlers KE, Karacay B, Fuller L, Bonthius DJ, Dailey ME: Transient activation of microglia following acute alcohol exposure in developing mouse neocortex is primarily driven by BAX-dependent neurodegeneration. Glia 2015;63:1694-1713.

6 Chastain LG, Sarkar DK: Role of microglia in regulation of ethanol neurotoxic action. Int Rev Neurobiol 2014;118:81-103.

7 Kreutzberg GW: Microglia: a sensor for pathological events in the CNS. Trends Neurosci 1996;19:312-318.

-8 Fernandez-Lizarbe S, Pascual M, Guerri C: Critical role of TLR4 response in the activation of microglia induced by ethanol. J Immunol 2009;183:4733-4744.

-9 Fernandez-Lizarbe S, Montesinos J, Guerri C: Ethanol induces TLR4/TLR2 association, triggering an inflammatory response in microglial cells. J Neurochem 2013;126:261-273.

10 Hanisch UK, Kettenmann H: Microglia: active sensor and versatile effector cells in the normal and pathologic brain. Nat Neurosci 2007;10:1387-1394.

11 Nimmerjahn A, Kirchhoff F, Helmchen F: Resting microglial cells are highly dynamic surveillants of brain parenchyma in vivo. Science 2005;308:1314-1318.

-12 Colton C, Wilcock DM: Assessing activation states in microglia. CNS Neurol Disord Drug Targets 2010;9:174-191.

13 Cherry JD, Olschowka JA, O'Banion MK: Neuroinflammation and M2 microglia: the good, the bad, and the inflamed. J Neuroinflammation 2014;11:98.

14 Krause DL, Muller N: Neuroinflammation, microglia and implications for anti-inflammatory treatment in Alzheimer's disease. Int J Alzheimers Dis 2010;2010: 


\section{Cellular Physiology Cell Physiol Biochem 2018;47:1411-1421 \begin{tabular}{l|l} 
and Biochemistry Published online: June 22, 2018 & $\begin{array}{l}\text { D) } 2018 \text { The Author(s). Published by S. Karger AG, Basel } \\
\text { www.karger.com/cpb }\end{array}$ \\
\hline
\end{tabular}}

15 McClain JA, Morris SA, Deeny MA, Marshall SA, Hayes DM, Kiser ZM, Nixon K: Adolescent binge alcohol exposure induces long-lasting partial activation of microglia. Brain Behav Immun 2011;25:S120-128.

16 Crews FT, Sarkar DK, Qin L, Zou J, Boyadjieva N, Vetreno RP: Neuroimmune Function and the Consequences of Alcohol Exposure. Alcohol Res 2015;37:331-341, 344-351.

17 He J, Crews FT: Increased MCP-1 and microglia in various regions of the human alcoholic brain. Exp Neurol 2008;210:349-358.

18 Tiwari V, Kuhad A, Chopra K: Suppression of neuro-inflammatory signaling cascade by tocotrienol can prevent chronic alcohol-induced cognitive dysfunction in rats. Behav Brain Res 2009;203:296-303.

-19 Alfonso-Loeches S, Pascual-Lucas M, Blanco AM, Sanchez-Vera I, Guerri C: Pivotal role of TLR4 receptors in alcohol-induced neuroinflammation and brain damage. J Neurosci 2010;30:8285-8295.

20 Ward RJ, Colivicchi MA, Allen R, Schol F, Lallemand F, de Witte P, Ballini C, Corte LD, Dexter D: Neuroinflammation induced in the hippocampus of 'binge drinking' rats may be mediated by elevated extracellular glutamate content. J Neurochem 2009;111:1119-1128.

21 Zhao YN, Wang F, Fan YX, Ping GF, Yang JY, Wu CF: Activated microglia are implicated in cognitive deficits, neuronal death, and successful recovery following intermittent ethanol exposure. Behav Brain Res 2013;236:270-282.

22 Zhang Y, Wei G, Wang Y, Jing L, Zhao Q: Gene expression profile analysis of rat cerebellum under acute alcohol intoxication. Gene 2015;557:188-194.

23 Wang Z, Takemori H, Halder SK, Nonaka Y, Okamoto M: Cloning of a novel kinase (SIK) of the SNF1/AMPK family from high salt diet-treated rat adrenal. FEBS Lett 1999;453:135-139.

-24 Lin X, Takemori H, Katoh Y, Doi J, Horike N, Makino A, Nonaka Y, Okamoto M: Salt-inducible kinase is involved in the ACTH/cAMP-dependent protein kinase signaling in Y1 mouse adrenocortical tumor cells. Mol Endocrinol 2001;15:1264-1276.

-25 Horike N, Takemori H, Katoh Y, Doi J, Min L, Asano T, Sun XJ, Yamamoto H, Kasayama S, Muraoka M, Nonaka Y, Okamoto M: Adipose-specific expression, phosphorylation of Ser794 in insulin receptor substrate-1, and activation in diabetic animals of salt-inducible kinase-2. J Biol Chem 2003;278:18440-18447.

-26 Katoh Y, Takemori H, Horike N, Doi J, Muraoka M, Min L, Okamoto M: Salt-inducible kinase (SIK) isoforms: their involvement in steroidogenesis and adipogenesis. Mol Cell Endocrinol 2004;217:109-112.

27 Feldman JD, Vician L, Crispino M, Hoe W, Baudry M, Herschman HR: The salt-inducible kinase, SIK, is induced by depolarization in brain. J Neurochem 2000;74:2227-2238.

28 Huang BS, White RA, Leenen FH: Possible role of brain salt-inducible kinase 1 in responses to central sodium in Dahl rats. Am J Physiol Regul Integr Comp Physiol 2012;303:R236-245.

29 Finsterwald C, Carrard A, Martin JL: Role of salt-inducible kinase 1 in the activation of MEF2-dependent transcription by BDNF. PLoS One 2013;8:e54545.

-30 Proschel C, Hansen JN, Ali A, Tuttle E, Lacagnina M, Buscaglia G, Halterman MW, Paciorkowski AR: Epilepsycausing sequence variations in SIK1 disrupt synaptic activity response gene expression and affect neuronal morphology. Eur J Hum Genet 2017;25:216-221.

-31 Hansen J, Snow C, Tuttle E, Ghoneim DH, Yang CS, Spencer A, Gunter SA, Smyser CD, Gurnett CA, Shinawi M, Dobyns WB, Wheless J, Halterman MW, Jansen LA, Paschal BM, Paciorkowski AR: De novo mutations in SIK1 cause a spectrum of developmental epilepsies. Am J Hum Genet 2015;96:682-690.

-32 Zhang Y, Wei G, Di Z, Zhao Q: miR-339-5p inhibits alcohol-induced brain inflammation through regulating NF-kappaB pathway. Biochem Biophys Res Commun 2014;452:450-456.

-33 Blednov YA, Harris RA: Metabotropic glutamate receptor 5 (mGluR5) regulation of ethanol sedation, dependence and consumption: relationship to acamprosate actions. Int J Neuropsychopharmacol 2008;11:775-793.

-34 Frank MG, Wieseler-Frank JL, Watkins LR, Maier SF: Rapid isolation of highly enriched and quiescent microglia from adult rat hippocampus: immunophenotypic and functional characteristics. J Neurosci Methods 2006;151:121-130.

35 Rehm J, Mathers C, Popova S, Thavorncharoensap M, Teerawattananon Y, Patra J: Global burden of disease and injury and economic cost attributable to alcohol use and alcohol-use disorders. Lancet 2009;373:22232233.

-36 Qin L, Crews FT: NADPH oxidase and reactive oxygen species contribute to alcohol-induced microglial activation and neurodegeneration. J Neuroinflammation 2012;9:5. 


\section{Cellular Physiology Cell Physiol Biochem 2018;47:1411-1421 and Biochemistry Published online: June 22, $2018 \quad \begin{aligned} & \text { DOI 10159/2 The Author(s). Published by S. Karger AG, Basel } \\ & \text { www.karger.com/cpb }\end{aligned}$ \\ Zhang et al.: SIK1 is Induced by Alcohol and Suppresses Inflammation}

37 Mochizuki H, Masaki T, Matsushita S, Ugawa Y, Kamakura K, Arai H, Motoyoshi K, Higuchi S: Cognitive impairment and diffuse white matter atrophy in alcoholics. Clin Neurophysiol 2005;116:223-228.

38 Qin L, He J, Hanes RN, Pluzarev 0, Hong JS, Crews FT: Increased systemic and brain cytokine production and neuroinflammation by endotoxin following ethanol treatment. J Neuroinflammation 2008;5:10.

39 Zhang J, Wu J, Zeng W, Yao K, Zu H, Zhao Y: Function of Thymosin Beta-4 in Ethanol-Induced Microglial Activation. Cell Physiol Biochem 2016;38:2230-2238.

40 Brust JC: Ethanol and cognition: indirect effects, neurotoxicity and neuroprotection: a review. Int J Environ Res Public Health 2010;7:1540-1557.

-41 Perry VH, Nicoll JA, Holmes C: Microglia in neurodegenerative disease. Nat Rev Neurol 2010;6:193-201.

42 Lee SC, Liu W, Dickson DW, Brosnan CF, Berman JW: Cytokine production by human fetal microglia and astrocytes. Differential induction by lipopolysaccharide and IL-1 beta. J Immunol 1993;150:2659-2667.

43 Hanisch UK: Microglia as a source and target of cytokines. Glia 2002;40:140-155.

44 Nakajima K, Kohsaka S: Microglia: neuroprotective and neurotrophic cells in the central nervous system. Curr Drug Targets Cardiovasc Haematol Disord 2004;4:65-84.

45 Lindenau J, Noack H, Asayama K, Wolf G: Enhanced cellular glutathione peroxidase immunoreactivity in activated astrocytes and in microglia during excitotoxin induced neurodegeneration. Glia 1998;24:252256.

46 Parkhurst CN, Yang G, Ninan I, Savas JN, Yates JR, 3rd, Lafaille JJ, Hempstead BL, Littman DR, Gan WB: Microglia promote learning-dependent synapse formation through brain-derived neurotrophic factor. Cell 2013;155:1596-1609.

47 Dougherty KD, Dreyfus CF, Black IB: Brain-derived neurotrophic factor in astrocytes, oligodendrocytes, and microglia/macrophages after spinal cord injury. Neurobiol Dis 2000;7:574-585.

-48 Mors K, Horauf JA, Kany S, Wagner N, Sturm R, Woschek M, Perl M, Marzi I, Relja B: Ethanol Decreases Inflammatory Response in Human Lung Epithelial Cells by Inhibiting the Canonical NF-kB-Pathway. Cell Physiol Biochem 2017;43:17-30.

-49 Yong Kim S, Jeong S, Chah KH, Jung E, Baek KH, Kim ST, Shim JH, Chun E, Lee KY: Salt-inducible kinases 1 and 3 negatively regulate Toll-like receptor 4-mediated signal. Mol Endocrinol 2013;27:1958-1968.

50 Johann S, Beyer C: Neuroprotection by gonadal steroid hormones in acute brain damage requires cooperation with astroglia and microglia. J Steroid Biochem Mol Biol 2013;137:71-81.

51 Kraft AD, McPherson CA, Harry GJ: Heterogeneity of microglia and TNF signaling as determinants for neuronal death or survival. Neurotoxicology 2009;30:785-793.

52 Crews F, Nixon K, Kim D, Joseph J, Shukitt-Hale B, Qin L, Zou J: BHT blocks NF-kappaB activation and ethanol-induced brain damage. Alcohol Clin Exp Res 2006;30:1938-1949.

-53 Lee IS, Lim J, Gal J, Kang JC, Kim HJ, Kang BY, Choi HJ: Anti-inflammatory activity of xanthohumol involves heme oxygenase-1 induction via NRF2-ARE signaling in microglial BV2 cells. Neurochem Int 2011;58:153160 . 